\title{
Selective visual attention for ugly and beautiful body parts in eating disorders
}

Citation for published version (APA):

Jansen, A. T. M., Nederkoorn, C., \& Mulkens, S. (2005). Selective visual attention for ugly and beautiful body parts in eating disorders. Behaviour Research and Therapy, 43(2), 183-196.

https://doi.org/10.1016/j.brat.2004.01.003

Document status and date:

Published: 01/01/2005

DOI:

10.1016/j.brat.2004.01.003

Document Version:

Publisher's PDF, also known as Version of record

Document license:

Taverne

Please check the document version of this publication:

- A submitted manuscript is the version of the article upon submission and before peer-review. There can be important differences between the submitted version and the official published version of record.

People interested in the research are advised to contact the author for the final version of the publication, or visit the DOI to the publisher's website.

- The final author version and the galley proof are versions of the publication after peer review.

- The final published version features the final layout of the paper including the volume, issue and page numbers.

Link to publication

\footnotetext{
General rights rights.

- You may freely distribute the URL identifying the publication in the public portal. please follow below link for the End User Agreement:

www.umlib.nl/taverne-license

Take down policy

If you believe that this document breaches copyright please contact us at:

repository@maastrichtuniversity.nl

providing details and we will investigate your claim.
}

Copyright and moral rights for the publications made accessible in the public portal are retained by the authors and/or other copyright owners and it is a condition of accessing publications that users recognise and abide by the legal requirements associated with these

- Users may download and print one copy of any publication from the public portal for the purpose of private study or research.

- You may not further distribute the material or use it for any profit-making activity or commercial gain

If the publication is distributed under the terms of Article $25 \mathrm{fa}$ of the Dutch Copyright Act, indicated by the "Taverne" license above, 


\title{
Selective visual attention for ugly and beautiful body parts in eating disorders
}

\author{
Anita Jansen*, Chantal Nederkoorn, Sandra Mulkens \\ Department of Experimental Psychology, Faculty of Psychology, University of Maastricht, P.O. Box 616, 6200 MD \\ Maastricht, The Netherlands
}

Received 8 August 2003; received in revised form 5 January 2004; accepted 14 January 2004

\begin{abstract}
Body image disturbance is characteristic of eating disorders, and current treatments use body exposure to reduce bad body feelings. There is however little known about the cognitive effects of body exposure. In the present study, eye movement registration (electroculography) as a direct index of selective visual attention was used while eating symptomatic and normal control participants were exposed to digitalized pictures of their own body and control bodies. The data showed a decreased focus on their own 'beautiful' body parts in the high symptomatic participants, whereas inspection of their own 'ugly' body parts was given priority. In the normal control group a self-serving cognitive bias was found: they focused more on their own 'beautiful' body parts and less on their own 'ugly' body parts. When viewing other bodies the pattern was reversed: high symptom participants allocated their attention to the beautiful parts of other bodies, whereas normal controls concentrated on the ugly parts of the other bodies. From the present findings the hypothesis follows that a change in the processing of information might be needed for body exposure to be successful.
\end{abstract}

(C) 2004 Elsevier Ltd. All rights reserved.

Keywords: Body image; Selective attention; Exposure; Eye movements; Cognitive bias; Eating disorders

\footnotetext{
${ }^{*}$ Corresponding author. Tel.: + 31-43-388-1910; fax: + 31-43-388-4196

E-mail address: a.jansen@psychology.unimaas.nl (A. Jansen).
} 


\section{Introduction}

Body-image disturbance is one of the main diagnostic features of eating disorders. Subjects with eating disorders feel fat and unattractive, and most of them show intense loathing of their bodies. They are preoccupied with their bodily appearance and show compulsive behaviors such as mirror checking and body measuring. Several authors argue that body disparagement is the key factor that underlies vulnerability to, and maintenance of, eating disorders (for example Cooley \& Toray, 2001; Rosen, 1990; Tuschen-Caffier, Vögele, Bracht, \& Hilbert, 2003; Stice, 2002; Wilson, Fairburn, \& Agras, 1997).

It is well documented now that the body-image disturbance is not a pure perceptual aberration and is better characterized as a cognitive-emotional distortion (e.g., Cash \& Deagle, 1997; Rushford \& Ostermeyer, 1997; Viken, Treat, Nosofsky, McFall, \& Palmeri, 2002; Williamson, 1996). Cognitive models of eating disorders propose that patients with eating disorders selectively attend to appearance cues (e.g., Hargreaves and Tiggemann, 2002; Viken et al., 2002; Williamson, Muller, Reas, \& Thaw, 1999), meaning that appearance stimuli are given priority and are amplified, while other stimuli are inhibited. The selective attention to appearance cues is thought to flow from underlying knowledge structures (schemas) that filter information and direct what a subject attends to: they guide attention to, memory for, and interpretation of stimuli in ways that serve to maintain the disorder (Hargreaves and Tiggemann, 2002; Viken et al., 2002; Vitousek \& Hollon, 1990; Williamson, 1996). The selective attention for appearance cues may be a maintenance factor in eating disorders.

Empirical data suggest that eating disordered patients demonstrate an attentional bias in the processing of appearance-related information. In modified Stroop color-naming tasks (see e.g., Williams, Mathews, \& MacLeod, 1996), eating disordered subjects need significantly more time to name the colors of body shape-related words than they need to name the colors of neutral words (e.g., Ben-Tovim \& Walker, 1991; Flynn \& McNally, 1999; Labarge, Cash, \& Brown, 1998). The color-naming interference for body shape-related words might mean greater attentional allocation to the body shape-related stimuli, in a very early stage of information processing. The processing resources are supposed to be automatically drawn toward the appearance-related information, even before that information has entered conscious awareness (Williams, Watts, MacLeod, \& Mathews, 1988). Although the Stroop interference in eating disorders is usually supposed to reflect early preferential processing of body shape words, it has been argued lately that an increased interference in modified Stroop tasks might but need not necessarily reflect increased attention to the content of the stimuli. It is difficult to distinguish attentional effects from other non-attentional processes such as response biases or distraction as a consequence of induced emotional arousal (MacLeod, Rutherford, Campbell, Ebsworthy, \& Holker, 2002). In fact, the modified Stroop task is not able to differentiate between attention, avoidance and other cognitive processes. Furthermore, because appearance cues are rather broad concepts, the modified Stroop merely offers a rough indication of (presumably attentional) processes during confrontation with appearance cues. Unsurprisingly, it shows selective interference to appearance cues in subjects who are preoccupied with their body shape. But it does not teach us what exactly happens when subjects with eating disorders are exposed to appearance cues.

In a series of elegant experiments, Tuschen-Caffier and co-workers (Hilbert, Tuschen-Caffier, \& Vögele, 2002; Tuschen-Caffier et al., 2003) found that prolonged body-image exposure induced 
negative emotions and cognitions in eating disordered patients. The participants in TuschenCaffier's studies described themselves during in vivo body-image exposure, being led by questions that the investigator read from an exposure manual. The activation of appearance schemas led to negative evaluations and lower mood in the eating disorder group. Although the eating disordered group spent significantly less time describing their waist, hips and bottom than a control group (Tuschen-Caffier et al., 2003), it is not clear whether the shorter descriptions reflect typical avoidance of these body parts, or that the participants were just feeling shame in the experimental situation, and were not able or did not want to describe the emotionally charged body parts so extensively. The use of self-reports is not the most reliable method to measure selective attention; schemas are underlying structures whereas self-reports are not only subjective to social desirability, but they are also based on the respondent's conscious awareness.

Cognitive processes like selective attention can thus be best assessed when using non-self-report measures and more direct indicators of information processing. To examine the attentional processes related to the body-image disturbance, and overcoming interpretative difficulties (whether the bias is related to the input (attentional) or output (responses) level, inherent in the modified Stroop task and self-reports), the present study used a more direct measure of visual attention during body exposure. To further investigate the body shape-related processing bias in eating disorders, eye movement registration (electroculography) as a direct index of selective visual attention was used while eating symptomatic and normal control participants were exposed to digitalized pictures of their own body and control bodies. During the exposure, the allocation of attention was measured exactly, and after the eye movement registration, the participants identified the most "ugly" and the most "beautiful" body part of the bodies they had seen (including their own). Given that the emotional content of stimuli is supposed to capture attention, it was hypothesized that during the exposure to their own bodies, the eating symptomatic participants would, in comparison to the normal controls, allocate their attention relatively more towards their self-identified ugly body part than to their self-identified beautiful body part, thereby reinforcing their cognitive body disparagement schema. Normal controls were expected to do exactly the opposite: to focus more on their own beautiful body parts than on their own ugly body parts. The amount of attention allocated to their self-identified ugly body parts is thus expected to be larger in the eating symptomatic group than in the normal control group. When looking at other bodies, eating symptomatic subjects were expected to focus on the beautiful parts of the other bodies, whereas normal controls were not expected to show any differences in visual attention for the ugly and beautiful parts of the other bodies. Finally, it was examined whether the exposure to the bodies induced a differential mood effect across the two groups. It was hypothesized that the eating symptomatic participants would be more depressed following short body-image exposure than the normal controls.

\section{Method}

\subsection{Participants}

Announcements at the university campus and an advertisement in a Dutch version of the journal Cosmopolitan asked for normal weight females with and without eating problems to take 
part in a study on the relation between character and perception. They were told that participants should be willing to go on a picture in underclothes without their head being visible, and they were asked for permission in writing that the headless pictures would be showed to others for research aims. A self-report eating disorder symptoms questionnaire was made by the authors and used to select eating symptomatic participants vs. normal controls. Of the participants who announced, the $25 \%$ lowest $(n=13)$ and the $25 \%(n=13)$ highest scorers on the self-report questionnaire were selected for participation. The high scorers were considered to be high in eating disorder symptoms. All participants signed the informed consent, and a professional photographer took the pictures in a studio. The background of the slides was blue and each model was dressed in the same underwear (a cream underpants and a cream bra). The model stood with the arms hanging loosely beside the body in a frontal view. After making the picture, the participant's weight, height, waist and hip circumference were determined.

The participants took part in the experiment that was announced as a 'perception task' 19 months after making the picture. At the end of the experiment, they completed the EDE-Q (Fairburn \& Beglin, 1994) and their height and weight were re-measured. During the experiment, three participants dropped out: one control subject appeared to be pregnant during the experiment and eye movement data recording failed for two participants (one high-symptom and one control participant), thus ending up with 12 eating symptomatic and 11 control participants.

\subsection{Assessment}

\subsubsection{Eating psychopathology}

The Eating Disorder Examination-Questionnaire (EDE-Q; Fairburn \& Beglin, 1994) was used to measure the presence and severity of specific eating psychopathology. The EDE-Q is a valid, effective and psychometrically sound self-report measure for the screening of eating disorders (Luce \& Crowther, 1999; Wilfley, Schwartz, Spurrell, \& Fairburn, 1997). The questionnaire version consists of 36 items, within a 28-day time frame, most of them loading on one of four subscales: restraint, eating concern, shape concern and weight concern. The Restraint Subscale measures the intention of the subject to restrict or avoid food intake (e.g., "Have you gone for long periods of time ( $8 \mathrm{~h}$ of more) without eating anything in order to influence your shape or weight?"), the Eating Concern Subscale measures troublesome obsessions with thoughts of calories or eating (e.g., "Has thinking about food or its calorie content made it much more difficult to concentrate on things you are interested in; for example, read, watch TV, or follow a conversation?), the Shape and Weight Concern Subscales measure troublesome pre-occupation with shape and weight and the importance of body shape and body weight for overall selfevaluation (e.g., "Has your shape $\backslash$ weight influenced how you think about (judge) yourself as a person?'). Higher scores reflect more eating psychopathology.

\subsubsection{Body evaluation}

The participant identified the most beautiful and the most ugly body part of each body presented on the screen, including her own. These body parts were given grades for appearance between 0 (very negative) and 10 (very positive). 


\subsubsection{Mood}

During the experiment state, mood was measured three times with the aid of a 0-100 mm Visual Analogue Scale asking "How do you feel now", and ranging from "depressed" to "happy".

\subsubsection{Selective attention}

The time that was spent looking at the most ugly vs. the most beautiful body parts during the body exposure was measured with the SMI (SensoMotoric Instruments, Berlin, Germany) Remote Eyetracking Device (RED), with an angular resolution of less than $0.5^{\circ}$. This device consists of an infrared source, which was aimed at the participant's eye at a distance of about $90 \mathrm{~cm}$, and an infrared camera. Rays from the infrared source were reflected by the retina and picked up by the camera, which generated a high-resolution image of the eye movements and pupil size on a computer screen. The body pictures were presented for a relatively long period of time $(30 \mathrm{~s})$ to give the opportunity to scan and re-scan body parts. They were presented on a television screen that was placed at a distance of $1 \mathrm{~m}$ from the participant who was seated in an adjustable chair. The software controlling the stimulus presentation was programmed in ERTS (Experimental Run Time System, Beringer, 1996). Both the percentage of time spent looking at specific body parts and the amount of fixations (defined as continuously watching more than 300 milliseconds a particular body part) were monitored, as an operationalization of selective attention.

\subsubsection{Pupil size and eye blinking}

Pupil diameters were measured in screen pixels, at a rate of $50 \mathrm{~Hz}$, that is every $20 \mathrm{~ms}$. The frequency of eye blinking during stimulus presentation was also provided by the eyetracking device. The pupil size data and the amount of eye blinks were analyzed by means of 2 (Group: Eating Symptomatic vs. Control) $\times 2$ (Body: Self vs. Other) analysis of variance (ANOVA).

\subsection{Procedure}

Each participant was run individually. After she entered the laboratory, she completed the mood VAS and was invited to sit in a chair in front of a television screen. She was instructed to sit quietly and she was told that the size of her pupils would be measured during viewing some pictures of female bodies. Nothing was told about the eye movements. After calibration, eye movements and pupil dilatation were registered during the presentation of a control body, the participants own body and another control body, in succession. The bodies were presented for $30 \mathrm{~s}$ each and between the bodies there was a $5 \mathrm{~s}$ gap. The participant was told beforehand that she had to look at the pictures and that she would first be presented someone else's body, then her own body, and then again someone else's body. The order of the two control bodies was balanced.

After having viewed the three slides for the first time, eye movement registration stopped and the participant completed the s mood VAS. Then, she was invited to look at the pictures again. Each body was presented again, for $1 \mathrm{~min}$ now, and the participant identified the ugliest and the most beautiful part of each body. The ugliest and most beautiful body parts were given a grade between 0 (very negative) and 10 (very positive). Then, the participant completed the mood VAS again, and she completed the EDE-Q. Her weight and height were determined, and she was paid a 
small fee for participation. The participants were debriefed in writing after finishing the whole experiment.

\section{Results}

\subsection{Data analysis}

Every participant had identified the ugliest and the most beautiful body part of herself and of the two control bodies. These ugliest and most beautiful body parts were defined as objects in the eye movement analysis program, and the percentage of time the participant spent looking at these body parts and the amount of fixations $(>300 \mathrm{~ms})$ in that body part were calculated. A mean for both control bodies was calculated to correct for idiosyncratic deviations of the control bodies. So, for each participant, we ended up with attention data for the ugliest and for the most beautiful body part, of both her own body and the mean control body. These data were further analyzed in a 2 (Group: Eating Symptomatic vs. Control) $\times 2$ (Body: Self vs. Other) $\times 2$ (Evaluation: Ugly vs. Beautiful) ANOVA. Dependent variables were (1) the percentage of time the participant looked at a body part and (2) the amount of fixations in a body part. The mood data were analyzed in a 2 (Group: Eating Symptomatic vs. Control) $\times 3$ (Time: pre-exposure, after exposure, after rating) ANOVA. Furthermore, mean pupil size and the amount of eye blinks were calculated during exposure to own body and the mean control body.

\subsection{Participant characteristics}

The characteristics of the participants are given in Table 1. During testing, there were no differences between both groups in age, body mass index (BMI) ${ }^{1}$ and waist-hip ratio (WHR). ${ }^{2}$ Comparing the BMI at the moment the picture was made (BMI high-symptomatic group: $M=21.6, S D=2.0$; normal controls: $M=20.7, S D=1.6 ; t(21)=1.2, \mathrm{NS})$ and at the moment of testing (BMI high-symptomatic group: $M=22.3, S D=3.2$; normal controls: $M=21.2$, $S D=1.5 ; t(21)=1.1$, NS) showed no significant differences between groups at both times of measurement, and also no significant differences within the groups between both measurements. The small increase in BMI between picture taking and participation in the experiment was not significant for the high symptomatic group, $t(11)=1.4$, NS, and marginally significant for the normal control group, $t(10)=1.9, p=0.08$. The BMIs on the pictures correlated significantly with the BMIs during the experiment, $r=0.83, p<0.01$. The small nonsignificant weight increase might reflect a real small raise in weight from picture taking to participation in the experiment, but it might also follow from experimental variations, e.g. the use of other scales or time of day.

At the moment of testing, the high-symptom group showed more eating disorder symptoms: they scored significantly higher on eating restraint, eating, weight and shape concerns, and had a significantly higher EDE-Q global score. The EDE-Q shape concerns of the present sample $(M=3.7)$ were about as high as the shape concerns of a bulimic sample $(M=3.8$; Agras, Walsh,

\footnotetext{
${ }^{1}$ The ratio of weight to squared height $\left(\mathrm{kg} / \mathrm{m}^{2}\right)$.

${ }^{2}$ The ratio of waist circumference to hip circumference.
} 
Table 1

Participant characteristics

\begin{tabular}{llll}
\hline & $\begin{array}{l}\text { Eating symptomatic } \\
(n=12) \mathrm{M}(\mathrm{sd})\end{array}$ & $\begin{array}{l}\text { Normal controls } \\
(n=11) \mathrm{M}(\mathrm{sd})\end{array}$ & $t(21)$ \\
\hline Age (yrs) & $24.4(3.7)$ & $23.2(2.3)$ & 0.9 \\
Body Mass Index (BMI) & $22.3(3.2)$ & $21.2(1.5)$ & 1.1 \\
Waist-Hip Ratio (WHR) & $0.72(0.04)$ & $0.72(0.06)$ & 0.08 \\
EDE-Q $^{\mathrm{a}}$ restraint & $2.3(1.4)$ & $0.5(0.5)$ & $3.8^{* *}$ \\
EDE-Q eating concern & $2.0(1.7)$ & $0.2(0.1)$ & $3.5^{* *}$ \\
EDE-Q shape concern & $3.7(1.4)$ & $0.8(0.5)$ & $6.7^{* *}$ \\
EDE-Q weight concern & $3.2(1.1)$ & $0.5(0.5)$ & $7.2^{* *}$ \\
EDE-Q global score & $2.8(1.2)$ & $0.5(0.3)$ & $6.1^{* *}$ \\
\hline
\end{tabular}

$* * p<0.005$.

${ }^{\mathrm{a}} \mathrm{EDE}-\mathrm{Q}=$ eating disorder examination questionnaire.

Table 2

Grades (0-10) given by the eating symptomatic and normal control participants, for the most ugly and the most beautiful parts of their own body and the control body

\begin{tabular}{llll}
\hline & $\begin{array}{l}\text { Eating symptomatic } \\
(n=12) \mathrm{M}(\mathrm{sd})\end{array}$ & $\begin{array}{l}\text { Normal controls } \\
(n=11) \mathrm{M}(\mathrm{sd})\end{array}$ & $t(21)$ \\
\hline Most beautiful part of own body & $7.5(1.0)$ & $8.0(0.4)$ & 1.6 \\
Ugliest part of own body & $2.8(1.3)$ & $4.6(1.5)$ & $3.1^{*}$ \\
Most beautiful part of control body & $8.1(0.8)$ & $7.8(0.4)$ & 0.8 \\
Ugliest part of control body & $3.6(1.3)$ & $5.0(0.8)$ & $3.3^{*}$ \\
\hline
\end{tabular}

${ }^{*} p<0.005$

Fairburn, Wilson, \& Kraemer, 2000). The other EDE-Q scores of the current sample were a bit lower than the EDE scores of subjects diagnosed with an eating disorder, in particular the restraint score was lower (e.g., Agras et al., 2000; Hay \& Fairburn, 1998). The current EDE-Q scores were about as high as the EDE scores of an Eating Disorders Not Otherwise Specified sample in Hay and Fairburn (1998).

\subsection{The ugliest and most beautiful body parts}

Each participant identified the ugliest and the most beautiful parts of both their own body and the control bodies. They rated these body parts with a grade between 0 (negative) and 10 (positive). Table 2 shows that there were no differences between the eating symptomatic and control participants in grades given for the most beautiful body parts, of both the control body and their own body. But the grades for the ugliest body parts given by the eating symptomatic participants were significantly lower than the grades for the ugliest body parts given by the control participants, both for the control body and own body. The ugliest parts of own body mentioned by the eating symptomatic participants were upper legs (4 times), hips (4 times), belly ( 3 times) 
and knees (1 time). The ugliest parts of own body mentioned by the normal controls were upper legs (7 times), lower legs (1 time), hips (1 time) and knees (2 times).

\subsection{Selective attention for ugly and beautiful body parts}

Exploration of the data showed that the percentage of time looking at the most beautiful part of their own bodies was not normally distributed (Shapiro-Wilks $=0.72, p<0.01$ ). One extreme outlier was identified by SPSS (boxplot): the score of a high-symptom participant was exactly 3 standard deviations above the mean (between 1.5 and 3 box length from the upper edge of the boxplot), and the gap between this participant and the previous was $1.3 \mathrm{sd}$. The participant was excluded from the eye movement analysis.

\subsection{Percentage of time looking}

Fig. 1 shows the mean $\%$ of time looking at beautiful and ugly body parts by eating symptomatic participants (Fig. 1a) and normal controls (Fig. 1b). The 2 (Group: Eating Disordered vs. Control) $\times 2$ (Body: Self vs. Other) $\times 2$ (Evaluation: Ugly vs. Beautiful) ANOVA on the percentage of time looking resulted in a significant three-way Group $\times$ Body $\times$ Evaluation interaction, $F(1,20)=5.5, p=0.03$. This interaction effect was further explored in two separate ANOVAs for the eating symptomatic and the normal control participants. For the eating symptomatic participants, the 2 (Body: Self vs. Other) $\times 2$ (Evaluation: Ugly vs. Beautiful) ANOVA on the percentage of time looking showed no main effects but a significant interaction effect, $F(1,10)=4.98, p=0.05$. Furter $t$-tests showed that the high symptom group spent significantly more time looking at their self-identified ugliest body part than at their self-identified most beautiful body part, $t(10)=3.8, p<0.005$, whereas the control participants spent as much


(a)

(b)
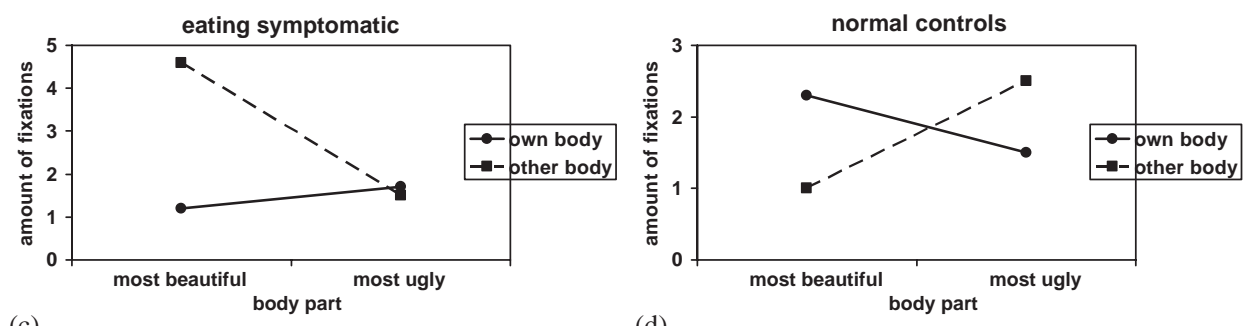

(d)

Fig. 1. The \% of looking time (a) and (b) and amount of fixations (c) and (d) into the most beautiful and most ugly body parts of the participants own body $(\mathbf{O})$ and a control body $(\mathbf{\square})$ for eating symptomatic $(n=11)$ and normal control $(n=11)$ participants. 
time looking at their own ugliest body part and their own most beautiful body part, $t<1$ (see Fig. $1 \mathrm{a}+\mathrm{b}$ ). For the normal control participants, the 2 (Body: Self vs. Other) $\times 2$ (Evaluation: Ugly vs. Beautiful) ANOVA on the percentage of time looking showed no significant main or interaction effects. Although the eating symptomatic participants spent more time looking at their selfidentified ugliest body part than at their self-identified most beautiful body part, there was no difference in the time looking at the ugly body parts between eating symptomatic and normal control participants, $t(20)<1$, NS. The figures show, and a $t$-test confirms, that the main difference between the eating symptomatic participants and the normal controls is the $\%$ of time they spent looking at their own most beautiful body part, $t(20)=2.1, p<0.05$.

\subsection{Amount of fixations}

Fig. 1 also shows the amount of fixations in beautiful and ugly body parts by the eating symptomatic participants (Fig. 1c) and the normal controls (Fig. 1d). The fixation analysis showed the same pattern as the \% of time looking analysis: the 2 (Group: Eating Disordered vs. Control $) \times 2$ (Body: Self vs. Other $) \times 2$ (Evaluation: Ugly vs. Beautiful) ANOVA on the amount of fixations in a body part resulted in a significant three-way Group $\times$ Body $\times$ Evaluation interaction, $F(1,20)=4.7, p<0.05$. This interaction effect was further explored in two separate ANOVAs for the eating symptomatic and the normal control participants. For the eating symptomatic participants, the 2 (Body: Self vs. Other) $\times 2$ (Evaluation: Ugly vs. Beautiful) ANOVA on the amount of fixations showed no significant effects. Fig. 1c shows that the eating symptomatic participants did not fixate more in their self-identified ugliest body part than the controls, but when looking at another body the eating symptomatic participants were inclined to fixate on the beautiful parts of that body. For the normal control participants, the fixations ANOVA showed no significant main effects and a marginally significant interaction, $F(1,10)=3.1, p=0.11$. Fig. 1d shows that the normal controls show a trend to fixate more into the ugly parts of somebody else's body, and less into the beautiful parts of that body, while they tend to give more attention to the beautiful parts of their own body at the cost of their own ugly parts.

In sum, when looking at their own body, eating symptomatic participants avoid looking at their beautiful body parts and concentrate at their own ugly body parts, whereas when they look at another body they focus on the beautiful parts of that body. The normal controls showed exactly the opposite pattern: they looked more at their own beautiful parts than at their ugly parts, but when looking at someone else's body their attention shifts towards the ugly parts of that body.

\subsection{Mood}

All participants rated their mood on a 0-100 visual analogue scale (VAS) before being exposed to the bodies and after exposure to the bodies and after having evaluated the bodies (identifying the ugliest and most beautiful body part, and rating it). A 2 (Group) $\times 3$ (Time) ANOVA showed a main effect of Time, $F(2,42)=3.41, p<0.05$, and a significant Group $\times$ Time interaction, $F(2,42)=3.36, p<0.05$. Fig. 2 shows that the mood of the eating symptomatic participants decreased significantly after the body exposure. No further decrease emerged after they had 


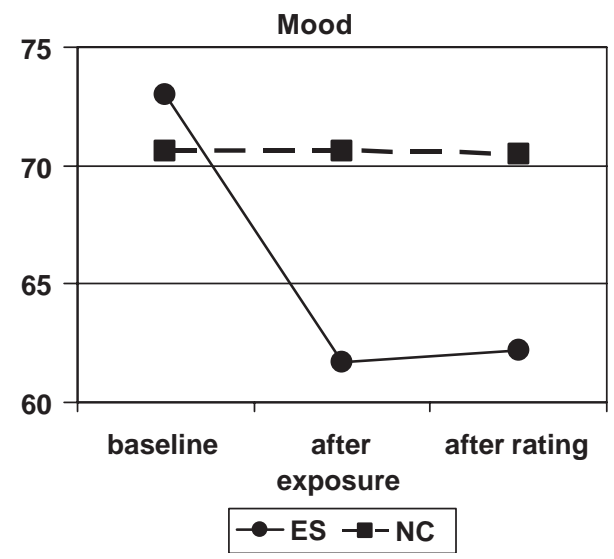

Fig. 2. Mood rated by the eating symptomatic participants (ES) and normal controls (NC) on a 0 (depressed) to 100 (happy) VAS before exposure (baseline), after exposure and after rating the bodies.

explicitly evaluated and rated the bodies. The mood of the normal controls was not at all influenced by being exposed to and evaluating the bodies.

\subsection{Pupil size and eye blinks}

\subsubsection{Pupil size}

The 2 (Group) $\times 2$ (Body) ANOVA showed a significant main effect for Body, $F(1,20)=7.0$, $p<0.02$, meaning that pupil dilation was observed when the participants looked at pictures of their own body (see Fig. 3a). The marginal significant interaction effect, $F(1,20)=2.9, p=0.1$, and paired $t$-tests show that in particular the high-symptom participants, and not the normal controls, had larger pupils when looking at their own body compared to looking at another body, $t(10)=2.6, p<0.03$. Also a marginally significant main effect for Group emerged, $F(1,20)=3.9$, $p=0.06$, indicating that during the experiment the high symptomatic participants had larger pupils than the normal controls. In sum, the pupil size data show that particularly the eating symptomatic participants responded with pupil dilation when viewing their own body.

\subsubsection{Eye blinks}

Eye blinks were defined as involuntary large rapid deflections, followed by a rapid return to baseline and typically lasting $120 \mathrm{~ms}$ (Andreassi, 2000). Analysis of the eye blink data by means of a 2 (Group) $\times 2$ (Body) ANOVA on the amounts of eye blinks showed no significant main effects (Body: $F<1$; Group: $F<1$ ). The interaction effect was however significant, $F(1,18)=5.8$, $p<0.03$, and the means show that, compared to the control body, the eyes of the eating symptomatic group blinked less when looking at their own body, whereas the eyes of the control group blinked somewhat more when looking at their own body (see Fig. 3b). 


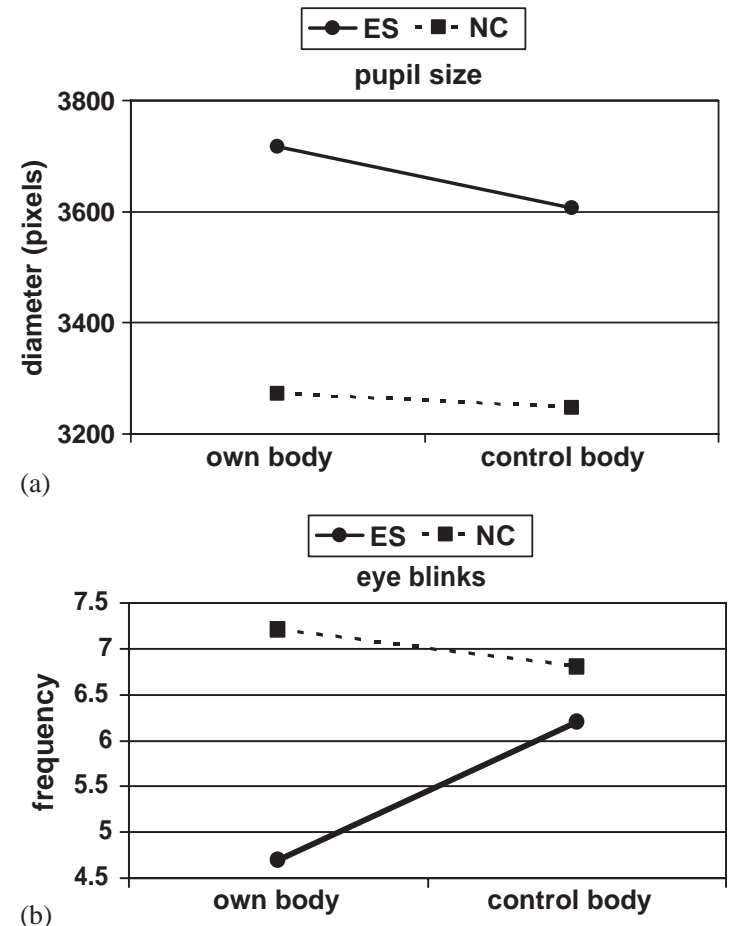

Fig. 3. Pupil size (diameter in pixels) and eye blink frequency during the exposure of eating symptomatic participants (ES) and NC to their own body and a control body.

\section{Discussion}

It was argued that it is highly important to know what happens during body exposure, and that the use of self-reports to measure attentional processes is not the most reliable method. In the present study a direct measure of attentional processing was used. By continuously monitoring eye movements and thus the allocation of attention during exposure to bodies, it was examined to what body parts eating symptomatic participants attend to, and which parts they avoid.

The data show that eating symptomatic participants allocate their attention more towards their self-identified ugly body part than to their self-identified beautiful body part, thereby supporting data from a former eye-gaze study in which it was found that eating disordered patients focused on the parts of the body they were most dissatisfied (Freeman et al., 1991). When looking at another body the eating symptomatic participants paid most attention to the beautiful part of that body. Normal controls did exactly the opposite: they focused more on their own beautiful body part than on their own ugly body part, while they directed their attention more to the ugly part of another body than to beautiful part.

Apart from the visual scanning patterns being more or less opposite to each other, a critical difference between the groups was the amount of attention paid to beautiful body parts: the results show that eating symptomatic participants spend less time looking at their own beautiful body parts than normal controls did. Paying more attention to one's own positive body parts than 
to one's own negative body parts might reflect a self-serving cognitive bias in the normal controls, and it has been argued repeatedly that positive biases such as the self-serving bias contribute to normal individuals' mental health and well-being. Biased thinking that favors own beautiful body parts might protect high body esteem, whereas a reduced self-serving body bias or even an absence of it (focusing less or not at all at positive body parts and more or totally at negative body parts) might maintain low body esteem and shape concerns in eating disorders. If it is indeed a failure to focus on their own beautiful body parts, treatments might benefit from incorporating procedures in eating disordered or body dysmorphic patients to learn to focus more on their good-looking parts.

The pupillary data show that the size of the pupils of eating symptomatic participants was significantly dilated when viewing their own body. Many studies have demonstrated that pupil dilation is a reliable correlate of cognitive load (Andreassi, 2000; Granholm, Asarnow, Sarkin, \& Dykes, 1996; Siegle, Granholm, Ingram, \& Matt, 2001), meaning that the amplitude of the pupillary response is an index of the processing demands required during the task. When participants allocate maximal resources to a task, dilation occurs: the pupils widen more under conditions of increased cognitive processing load (Andreassi, 2000). The pupil size increase in the present eating symptomatic group during the exposure to their own bodies might thus reflect increased attentional allocation to their own bodies during the own-body exposure. The blinking data are in line with these findings: a decreased blink rate is an index of increased attention and concentration (Gregory, 1998). During periods of concentrated mental activity, the frequency of blinking decreases (Gregory, 1998; Stern \& Dunham, 1990), and this is exactly what we found in the present sample of eating symptomatic participants: they blinked less when attending their own bodies. The pupillary dilation and decreased eye blinking thus show that viewing their own bodies elicited increased attention and concentrated mental activity in the eating symptomatic participants instead of avoidance.

Body exposure therapy is a widely used popular technique in clinical settings nowadays, but little is known about the mechanism and effects of the exposure treatment. The body exposure in this study lowered the mood of eating symptomatic participants dramatically, whereas the mood of normal controls was not influenced by the exposure. Although no mirror was used, and body exposure in the mirror might be different from body exposure on a TV screen as was the case in this study, the present findings show that mere exposure to one's own body induces negative emotions as a consequence of activating negative appearance-related schemas. The data also show that the eyes move favoring the "ugly" body parts with increased attention vs. the "beautiful" parts with decreased attention. It is not clear whether repeated mere exposures of longer duration are really helpful. Patients might continue selectively attending to their ugly parts and reinforce their "ugly" body schemes. Although some preliminary data show that habituation takes place during body-image exposure (Hilbert et al., 2002; Key et al., 2002; Rushford \& Ostermeyer, 1997; Tuschen-Caffier et al., 2003), it is not obvious that the habituation leads to a change in the processing of information. If modified information processing is needed for recovery, it is highly important for successful treatment that the exposure leads to a change in attentional processing and the related negative thinking. Apart from replicating this study with a large clinical sample, a main empirical question for further research thus is whether a simultaneous cognitive training, which changes the processing of specific body part evaluations by focusing on the positive body parts rather than on the negative ones, is needed to obtain body disparagement reduction. 


\section{Acknowledgment}

The authors are grateful to Pascal van Gerven for his valuable contribution to the Eyetracking report.

\section{References}

Agras, W. S., Walsh, T., Fairburn, C. G., Wilson, G. T., \& Kraemer, H. C. (2000). A multicenter comparison of cognitive-behavioral therapy and interpersonal psychotherapy for bulimia nervosa. Archives of General Psychiatry, 57, 459-466.

Andreassi, J. L. (2000). Psychophysiology. Human behavior and physiological response. London: Lawrence Erlbaum Associates.

Ben-Tovim, D., \& Walker, M. (1991). Further evidence for the Stroop as a quantitative measure of psychopathology in eating disorders. International Journal of Eating Disorders, 10, 609-613.

Beringer, J. (1996). Experimental Run Time System (ERTS) [computer software]. BeriSoft, Frankfurt: Germany.

Cash, T. F., \& Deagle, E. A. (1997). The nature and extent of body-image disturbances in anorexia nervosa and bulimia nervosa: A meta-analysis. International Journal of Eating Disorders, 22, 107-125.

Cooley, E., \& Toray, T. (2001). Body image and personality predictors of eating disorder symptoms during the college years. International Journal of Eating Disorders, 30, 28-36.

Fairburn, C. G., \& Beglin, S. J. (1994). The assessment of eating disorders: Interview or self-report questionnaire?. International Journal of Eating Disorders, 16, 363-370.

Flynn, S. V., \& McNally, R. (1999). Do disorder-relevant cognitive biases endure in recovered bulimics?. Behavior Therapy, 30, 541-553.

Freeman, R., Touyz, S., Sara, G., Rennie, Ch., Gordon, E., \& Beumont, P. (1991). In the eye of the beholder: Processing body shape information in anorexic and bulimic patients. International Journal of Eating Disorders, 6 , 709-714.

Granholm, E., Asarnow, R. F., Sarkin, A. J., \& Dykes, K. L. (1996). Pupillary responses index cognitive resource limitations. Psychophysiology, 33, 457-461.

Gregory, R. L. (1998). O1_MRKO1_MRKEye and brain. The psychology of seeing. Oxford: Oxford University Press.

Hargreaves, D., \& Tiggemann, M. (2002). The role of appearance schematicity in the development of adolescent body dissatisfaction. Cognitive Therapy and Research, 26, 691-700.

Hay, Ph., \& Fairburn, C. G. (1998). The validity of the DSM-IV scheme for classifying bulimic eating disorders. International Journal of Eating Disorders, 23, 7-15.

Hilbert, A., Tuschen-Caffier, B., \& Vögele, C. (2002). Effects of prolonged and repeated body image exposure in bingeeating disorder. Journal of Psychosomatic Research, 52, 137-144.

Key, A., George, C. L., Beattie, D., Stammers, K., Lacey, H., \& Waller, G. (2002). Body image treatment within an inpatient program for anorexia nervosa: The role of mirror exposure in the desensitization process. International Journal of Eating Disorders, 31, 185-190.

Labarge, A. S., Cash, T. F., \& Brown, T. A. (1998). Use of a modified Stroop task to examine appearance-schematic processing in college women. Cognitive Therapy and Research, 22, 179-190.

Luce, K. H., \& Crowther, J. H. (1999). The reliability of the eating disorder examination-self-report questionnaire version (EDE-Q). International Journal of Eating Disorders, 25, 349-351.

MacLeod, C., Rutherford, E., Campbell, L., Ebsworthy, G., \& Holker, L. (2002). Selective attention and emotional vulnerability: Assessing the causal basis of their association through the experimental manipulation of attentional bias. Journal of Abnormal Psychology, 111, 107-123.

Rosen, J. C. (1990). Body image disturbances in eating disorders. In T. F. Cash, \& T. Pruzinsky (Eds.), Body images. Development, deviance and change (pp. 190-214). New York: The Guilford Press.

Rushford, N., \& Ostermeyer, A. (1997). Body image disturbances and their change with videofeedback in anorexia nervosa. Behaviour Research and Therapy, 5, 389-398. 
Siegle, G. J., Granholm, E., Ingram, R. E., \& Matt, G. E. (2001). Pupillary and reaction time measures of sustained processing of negative information in depression. Society of Biological Psychiatry, 49, 624-636.

Stern, J. A., \& Dunham, D. N. (1990). The ocular system. In J. T. Cacioppo, \& L. G. Tassinary (Eds.), Principles of psychophysiology: Physical, social and inferential elements (pp. 513-553). Cambridge: Cambridge University Press.

Stice, E. (2002). Risk and maintenance factors for eating pathology: A meta-analytic review. Psychological Bulletin, 128, 825-848.

Tuschen-Caffier, B., Vögele, C., Bracht, S., \& Hilbert, A. (2003). Psychological responses to body shape exposure in patients with bulimia nervosa. Behaviour Research and Therapy, 41, 573-586.

Viken, R. J., Treat, T. A., Nosofsky, R. M., McFall, R. M., \& Palmeri, T. J. (2002). Modeling individual differences in perceptual and attentional processes related to bulimic symptoms. Journal of Abnormal Psychology, 111, 598-609.

Vitousek, K. B., \& Hollon, S. D. (1990). The investigation of schematic content and processing in eating disorders. Cognitive Therapy and Research, 14, 191-214.

Wilfley, D. E., Schwartz, M. B., Spurrell, E. B., \& Fairburn, C. G. (1997). Assessing the specific psychopathology of binge eating disorder patients: Interview or self-report?. Behaviour Research and Therapy, 35, 1151-1159.

Williams, J. M. G., Mathews, A., \& MacLeod, C. (1996). The emotional Stroop task and psychopathology. Psychological Bulletin, 120, 3-24.

Williams, J. M. G., Watts, F. N., MacLeod, C., \& Mathews, A. (1988). Cognitive psychology and emotional disorders. Chicester, England: Wiley.

Williamson, D. A. (1996). Body image disturbance in eating disorders: A form of cognitive bias?. Eating Disorders, 4 , $47-58$.

Williamson, D. A., Muller, S. L., Reas, D. L., \& Thaw, J. M. (1999). Cognitive bias in eating disorders: Implications for theory and treatment. Behavior Modification, 23, 556-577.

Wilson, G. T., Fairburn, G. C., \& Agras, W. S. (1997). Cognitive-behavioural therapy for bulimia nervosa. In D. M. Garner, \& P. E. Garfinkel (Eds.), Handbook of treatment for eating disorders. New York: Guilford Press. 